\title{
TRABALHADORES DESEMPREGADOS E LUTA COLETIVA: dificuldades e possibilidades
}

\author{
Giuliana Franco Leal
}

\begin{abstract}
Este artigo propõe uma discussão sobre as possibilidades de reação coletiva ao desemprego por parte dos trabalhadores desempregados. Realiza-se uma revisão bibliográfica e uma pesquisa de campo de caráter qualitativo, baseada em entrevistas semiestruturadas com trabalhadores que não fazem parte de movimentos sociais envolvidos com a questão do desemprego, no município de Campinas (SP), e de militantes de um movimento de trabalhadores desempregados, nas cidades de Campinas e do Rio de Janeiro. Desenvolvem-se hipóteses sobre quais são os obstáculos e os impulsos para que trabalhadores desempregados se organizem em associações pela defesa de seus interesses.

PALAVRAS-CHAVE: desemprego, trabalhadores desempregados, movimento social, classes sociais, luta social.
\end{abstract}

\section{INTRODUÇÃO}

O desemprego, em qualquer grau que se apresente, compõe uma questão social e sociologicamente relevante porque evidencia a fragilidade dos trabalhadores e coloca em questão as possibilidades de a sociedade capitalista realizar o mínimo de bem-estar para seus membros. Embora as taxas de desemprego e de trabalho informal tenham diminuído desde meados da década de 2000, ainda existe um grupo de desempregados e de trabalhadores informais que não pode ser considerado residual, ${ }^{1}$ o que faz com que a discussão sobre o desemprego permaneça atual.

Pensar o desemprego - e o seu combate envolve refletir sobre as possibilidades de reação coletiva dos próprios trabalhadores desempregados em relação a esse fenômeno. Este artigo propõe a discussão dessa questão. Procuramos escla-

* Doutora em Sociologia. Professora do Campus de Macaé da Universidade Federal do Rio de Janeiro.

Avenida São José do Barreto, s/n - São José do Barreto Macaé - Rio de Janeiro - Brasil. Cep: 27.971-550. giulianafrancoleal@yahoo.com.br

${ }^{1}$ Sobre essa discussão, ver Leite (2009). recer quais são os obstáculos e os impulsos para que trabalhadores desempregados se organizem em associações pela defesa de seus interesses.

Desenvolveremos algumas hipóteses a partir de uma revisão da bibliografia sobre o tema e das primeiras etapas de uma pesquisa de campo realizada com trabalhadores desempregados. Na pesquisa de campo, ainda em andamento, foram realizadas, até o momento, entrevistas semiestruturadas com 32 trabalhadores em busca de emprego no Centro de Apoio ao Trabalhador (CPAT) na cidade de Campinas (SP), todos eles sem nenhuma vinculação com movimentos sociais, em dezembro de 2009, e com dois militantes do Movimento dos Trabalhadores Desempregados (MTD), dos municípios de Campinas e do Rio de Janeiro, respectivamente em novembro de 2009 e em abril de 2010. Trata-se de dois municípios localizados em importantes regiões metropolitanas do país, com uma camada heterogênea de trabalhadores desempregados entre a população, e com um desenvolvimento pequeno dos movimentos de trabalhadores desempregados.

Os temas abordados com os trabalhadores 
desempregados diziam respeito a seu perfil, suas experiências de trabalho e de desemprego, sua visão sobre as causas do desemprego e a maneira de resolvê-lo e, finalmente, seu conhecimento de movimentos de luta coletiva contra o desemprego e sua opinião sobre eles. As entrevistas com os militantes do MTD abordavam, além desses temas, o histórico de formação do movimento, sua participação, o perfil dos demais participantes e as dificuldades práticas encontradas na sua organização.

Ao longo do artigo, revela-se como a estigmatização do trabalhador desempregado, a vivência do desemprego como situação de inferioridade social, o isolamento e a despolitização do tema, associados à ausência de clareza sobre as causas do desemprego, implicam dificuldades para a luta coletiva. Por outro lado, expõe-se que as possibilidades de pensar e combater coletivamente o desemprego estão dadas quando os trabalhadores desempregados passam a perceber o desemprego como problema político e veem, na construção de movimentos sociais, a possibilidade de reelaboração de laços de solidariedade e de reconhecimento social.

\section{AS DIFICULDADES PARAA ORGANIZAÇÃO COLETIVA}

O desemprego é uma categoria social construída, o que implica que a maneira como uma sociedade, por meio de disputas internas, constrói uma visão dominante sobre o desemprego - a partir de uma visão dominante sobre o lugar e o papel do trabalho - desenha as possibilidades de organização e de luta em torno das questões envolvidas no tema.

No livro Sociologie du Chômage (1995a), Demazière mostra que a ideia de desemprego emerge com o desenvolvimento da sociedade industrial, com a correspondente relação salarial apoiada sobre o contrato de trabalho institucionalizado e coletivo. A categoria é construída para classificar certas situações que fogem à norma social do trabalho regular assalariado.
Como todas as categorias sociais, também essa se modifica na medida em que a sociedade se transforma. O aumento do desemprego tende a provocar uma afirmação mais institucionalizada da categoria, seja a partir da identificação dos próprios trabalhadores, seja por iniciativa governamental, na tentativa de estabelecer políticas públicas referentes ao tema (Demazière, 1995a).

Múltiplas variáveis estão imbricadas na categoria. Nas palavras de Demazière:

O desemprego não se define apenas por uma condição social objetiva (a privação de emprego), mas é também uma situação subjetiva (vivida de maneira variável pelos indivíduos) e também um estatuto reconhecido (enquadrado por instituições e regras). Ser desempregado [...] é uma condição que supõe uma dialética entre mecanismos socioeconômicos discriminantes, reivindicações individuais e lógicas institucionais. (1995a, p.4, trad. livre).

Desse modo, o desemprego pode ser focado de várias maneiras, como, por exemplo, um estatuto jurídico, uma experiência íntima, uma representação social ou uma categorização para ação administrativa. Consideramos que uma visão mais completa das questões relacionadas ao desemprego exige uma análise das relações entre suas várias faces. Mas cada uma delas pode ser enfatizada com diferentes matizes, conforme as intenções de quem se aproprie da categoria em seu discurso.

Os variados discursos, com diferentes enfoques, representam uma disputa, no campo das ideias, a respeito de como lidar com o desemprego. Tais diferenças estão pautadas em visões de mundo diversificadas, mas também em interesses divergentes. Quando um grupo se organiza coletivamente em torno das questões relativas ao desemprego, tem a necessidade de construir sua própria posição sobre o tema, mas ela dialoga com a(s) visão(ões) dominante(s) sobre o tema, que variam no tempo e no espaço, conforme as condições sociais, econômicas e políticas de uma sociedade, que incluem as posições de força nas disputas entre grupos com interesses específicos.

Pignoni (2006) reforça o argumento acima ao oferecer um estudo comparativo do desempre- 
go entre dois países, França e Itália. Sua premissa, confirmada pela pesquisa, consiste na concepção de que o desemprego é uma construção social, de modo que sua conformação e as representações sobre ele variam segundo a sociedade. Na França, o desemprego ganhou notoriedade pela sua massificação, tendo se tornado a grande questão social a partir da década de 1980, para estudiosos, políticos e opinião pública. A valorização do Estado de Bem-Estar Social, mesmo quando em crise, e o tratamento do desemprego como problema público facilitaram o surgimento de vários movimentos de trabalhadores desempregados e seu reconhecimento como interlocutores do Estado. ${ }^{2}$ Já na Itália, predomina a tendência histórica de resolver esse tipo de problema na dimensão privada a partir da rede de solidariedade primária (principalmente no interior da família), da fraqueza do sistema público de proteção social e da tradição patriarcal de resolução dos problemas relativos ao emprego (tende-se a proteger o emprego dos homens chefes de família, subestimando-se o desemprego de mulheres e jovens, mais acentuado). Nesse país, as mobilizações de desempregados foram menores e restritas principalmente às regiões mais pobres.

Guimarães (2002) igualmente enfatiza a importância de observar as diferenças de contexto de um país para outro, conforme as políticas de emprego adotadas, a amplitude e o formato dos sistemas de welfare, os sistemas industriais e suas relações, e a cultura mais ampla.

A própria Guimarães (2009) e sua equipe realizaram estudos comparativos entre o Brasil, a França e o Japão, mostrando as diferenças entre os mercados metropolitanos de Paris (1995-1998), Tóquio (1994-2001) e São Paulo (1994-2001), com a utilização de surveys longitudinais para confrontar trajetórias ocupacionais. Chegaram, assim, à tese de que "os padrões de transição ocupacional variam segundo a maneira como se institucionalizam, nas diferentes sociedades, os sistemas de emprego e de proteção social, os chamados 'regimes de

${ }^{2}$ É provavelmente por esse motivo que há tantos estudos sobre o desemprego na França, tendo a bibliografia francesa se constituído numa referência relevante para as pesquisas sobre o tema. welfares"' (Guimarães et al 2009, p.2). Em Paris, existe um sistema público, sólido e inclusivo; em Tóquio, um sistema privado pujante, mas seletivo; em São Paulo, uma experiência de proteção ao desemprego recente e restrita (datado da década de 80), construída sobre a base de um mercado com "desemprego recorrente" (em vez de "desemprego de longa duração”) e com dupla mobilidade, entre situações de ocupação e de desemprego e entre situações de atividade e inatividade.

Tais diferenças se refletem em variações nas representações sobre a procura de trabalho e os padrões de mobilização de recursos para a obtenção da ocupação: onde o padrão de duração dos vínculos é mais estável (caso do Japão), o desemprego é mais comumente vivido como privação individual da qual se procura sair com recurso à consulta a jornais e revistas (77,7\%), seguida de perto por agências públicas de emprego (65,2\%); na França, onde a proteção pela regulação normativa do desemprego é maior, o principal mecanismo é a procura direta no mercado, com suporte do sistema público de apoio ao desempregado; por fim, em São Paulo, os mecanismos que mais se destacam são as redes sociais, especialmente família e amigos próximos (79,5\%).

Guimarães (2002) também ressalta que as representações variam não apenas de uma sociedade para outra, mas de acordo com a evolução do problema no interior de uma mesma sociedade. Nesse sentido, mostra que, dentro do Brasil, a maneira de os desempregados identificarem-se e representarem-se tendeu a variar segundo a extensão da crise do desemprego e as consequentes possibilidades de retorno ou não à situação de trabalho anterior.

No campo político, em momentos nos quais o desemprego parece reflexo temporário de uma crise, os movimentos de desempregados podem ser agentes centrais da demanda por um sistema de regulação pública mais eficaz, sendo indicativos de que a condição de desempregado não é um estigma que desonra; ao contrário, ela pode ser assumida como um sinal diacrítico, portador de uma identidade, mesmo sendo ela construída a partir 
de um estatuto transitório. Nas condições do início dos anos 1980, o trabalhador, em vez de "desempregado", mantinha uma representação pela sua designação profissional anterior (por exemplo, como "metalúrgico”); ou seja, sua origem ocupacional continuava sendo provedora de autorreconhecimento e de reconhecimento pelos outros (em especial, pelo seu sindicato). Isso se tornava possível pela crença nas chances do retorno ao setor de origem. Tal construção subjetiva e o seu correlato institucional perderam sentido nos anos de crise da década seguinte, no Brasil (Guimarães, 2002).

No caso brasileiro, a história da categoria desemprego foi marcada por características do mercado de trabalho do país durante todo o século XX: vínculos de trabalho informais para mais da metade dos trabalhadores; alta rotatividade; grande disponibilidade de mão de obra; mecanismos de seguridade pouco extensivos. Assim, como assinala Jardim (2009), o desemprego fica muitas vezes mascarado pelo subemprego, inclusive em estatísticas oficiais. $^{3}$

Enfim, o desemprego foi subestimado no Brasil por muito tempo. Estudos sobre o desemprego, pensados nesses termos, somente se multi-

${ }^{3}$ No Brasil, as duas maiores pesquisas que permitem medir o desemprego são de tipo domiciliar. A Pesquisa Mensal de Desemprego (PME), do IBGE, é aplicada em seis regióes metropolitanas: Recife, Salvador, Belo Horizonte, Rio de Janeiro, São Paulo e Porto Alegre. Ela leva em conta apenas o desemprego aberto, isto é, relativo às pessoas em idade ativa (acima de 10 anos, embora a PME só leve em consideração os que estão acima de 15 anos até 2003 , $F \quad$ quando volta a ser de 10 anos), que não tenham exercido atividade remunerada e tenham procurado ativamente por trabalho num período de referência de 30 dias (até 2002, o período era de apenas 7 dias). Depois da mudança metodológica de 2003, o PME passou a reconhecer a categoria desalento, reconhecendo as situações em que as pessoas deixam de fazer parte da PEA de modo involuntário, ainda que esse reconhecimento tenha se dado de maneira restrita, deslocando essas pessoas para a categoria da inatividade. Por sua vez, a pesquisa de Emprego e Desemprego (PED) do Dieese, existente desde 1984, tem como principal inovação o esforço para definir e mensurar o desemprego oculto por trabalho precário ou por desalento. Tanto desemprego oculto como aberto entram na contagem total de desempregados. A população em idade ativa (PIA) é considerada a partir de 10 anos, pela realidade social do país, que leva muitas crianças a trabalhar. As diferenças metodológicas vão se aprofundar na definição da população economicamente ativa (PEA), que leva em consideração os seguintes critérios: procura efetiva de trabalho; disponibilidade para trabalhar (período de 12 meses); estar ou não em situação de trabalho; tipo de trabalho exercido (regular ou irregular) e necessidade de mudança de trabalho (sim ou não). plicaram no Brasil na década de 1990. Antes disso, a maior parte das pesquisas empregava, em maior medida, categorias como "marginalizados", "excluídos" e "trabalhadores informais". ${ }^{4}$ Políticas de combate ao desemprego ou de atenuação dos seus efeitos também foram tardias no país: o seguro-desemprego, por exemplo, embora previsto já na Constituição de 1946, só foi regulamentado por decreto em 1986, e apenas em 1990 se criou, de fato, um Programa Seguro-Desemprego (Jardim, 2009).

Com esses dados, fica mais fácil compreender que, no Brasil, a formação de movimentos de trabalhadores desempregados tenha sido tardia, se comparada com países europeus, cujos mercados de trabalho, bastante estruturados e formalizados, tornaram mais definida a separação entre atividade e inatividade.

Na Europa, desempregados entraram na cena pública por meio das "marchas da fome”, em vários países, durante os anos 1880; as mobilizações ganharam intensidade e visibilidade após a crise de 1929, principalmente na Inglaterra, por melhorias das condições de vida dos desempregados (aumento da indenização, fim das expulsões das moradias, gratuidade nos transportes, cuidados médicos etc.) e também por uma melhor repartição do trabalho (redução da jornada de trabalho, organização de grandes frentes de trabalho públicas, supressão de horas extras); finalmente, os movimentos reavivaram-se outra vez na década de 1970, novo momento de crise econômica e elevação do desemprego, com destaque para a França, onde esses movimentos têm uma aceitação especial, pois alguns deles passam a ser reconhecidos como interlocutores pelo Estado (caso do Movimento Nacional de Desempregados).

Já no Brasil, os movimentos de desempregados são pouco numerosos e têm baixa participa-

${ }^{4}$ Uma das exceções é o trabalho de Hirata e Humphfrey (1989), que analisa as trajetórias de operárias e operários que perderam seus empregos na crise econômica pela qual o Brasil passou no início da década de 1980. A pesquisa leva à conclusão de que há três fatores que influenciam as estratégias operárias face à perda do emprego: a força da identidade profissional, a posição do(a) trabalhador(a) na família quanto ao papel de provedor(a) $\mathrm{e}$ as diferenças de oportunidades oferecidas pelo mercado de trabalho segundo o sexo e a qualificação. 
ção. Manifestações estimuladas pelo desemprego apareceram na década de 1980, mas não foram duradouras. É o caso do movimento de Luta Contra o Desemprego (MLCD), atuante na cidade de São Paulo entre 1983 e 1985, e dispersado pela própria desarticulação interna ${ }^{5}$ (Del Prette, 1990). Em 2000, surgiu o Movimento de Trabalhadores Desempregados (MTD) em Porto Alegre, com a mobilização de famílias de desempregados em busca de melhorias nas condições de vida, trabalho e moradia, a partir da iniciativa de militantes pela reforma urbana (Goulart, 2003), ligados à Consulta Popular. O movimento se expandiu, buscou articulações com outras cidades e estados e chegou a promover seu primeiro encontro nacional em abril de 2007, com o desafio de construir uma identidade nacional. Mas basta procurar informações sobre o movimento para perceber que sua visibilidade é pequena.

Retomando a questão do mascaramento do desemprego pelo subemprego, em países com alto grau de informalidade, levantamos a hipótese de que não é só na definição das categorias de mensuração que o desemprego se confunde com o subemprego. No contexto descrito, trabalhadores com empregos intermitentes e precários podem tender a não se reconhecer como desempregados, acostumados que estão a esse tipo de situação como o padrão de normalidade.

Como sugere o trabalho de Jardim (2009), a falta de institucionalização da categoria desemprego e a pouca identificação dos trabalhadores sem trabalho assalariado ou com trabalho precário com essa categoria, no Brasil, formam um ciclo vicioso: se as pessoas não se identificam com a categoria, não pressionam os órgãos competentes pela sua institucionalização e, se ela não ocorre, paralisamse ou retardam-se as pesquisas e as políticas públicas relativas ao desemprego, e essa ausência de

\footnotetext{
${ }^{5}$ O MLCD atuava prioritariamente por meio de atos públicos, acampamentos e montagem de cartas e comissões para negociação; suas reivindicações principais eram a abertura de frentes de trabalho, benefícios para os trabalhadores desempregados (de seguro-desemprego a passes, cestas básicas e isenção das contas de água e luz), legalização da estabilidade no emprego e redução da jornada de trabalho de 48 para 40 horas semanais (Del Prette, 1990).
}

evidência e institucionalização da categoria a tornam menos significativa para a população.

Se existe uma tendência a haver um estigma sobre o desemprego em todas as sociedades nas quais o trabalho assalariado é a norma, é possível, no caso de países em que a norma é "se virar" em trabalhos eventuais e informais, que, para o trabalhador, admitir-se como desempregado possa ser ainda mais estigmatizante.

Em entrevistas com trabalhadores à procura de emprego, surgem afirmações que confirmam essa ideia:

Trabalho tem, o que não pode é a pessoa querer ficar esperando um [emprego] ótimo, com o ordenado que quer, onde quer, assinado, tudo bonitinho. Se o nego quer trabalhar, tem que aceitar o que tem, correr atrás, até vender coisa no semáforo a gente vende, se precisar, e consegue. E é trabalho, não é?

(Auxiliar de pedreiro desempregado, 53 anos, ensino fundamental incompleto, sem vinculação com movimentos sociais).

Aceitar qualquer tipo de trabalho é uma maneira não apenas de conseguir o sustento necessário, mas também de fugir à humilhação de estar "parado".

Pesquisadores, em um país com um mercado assalariado formal muito forte entre as décadas de 1930 e 1970, os franceses Demazière (1995b) e Schnapper (1994), afirmam que o desemprego é recorrentemente vivido como uma experiência de humilhação e inferioridade social, seja em classes médias ou baixas.

Ao comparar os dados obtidos em sua própria pesquisa empírica ${ }^{6}$ com um balanço dos estudos sobre o tema, Schnapper (1994) constata que os sentimentos de perturbação e inferioridade devem-se ao afastamento dos trabalhadores desempregados em relação à norma dominante nas sociedades de que fazem parte. Nas sociedades con-

\footnotetext{
${ }^{6}$ A pesquisa de Schnapper (1994) baseia-se em cem entrevistas livres, realizadas entre novembro de 1978 e junho de 1980 com pessoas inscritas como demandantes de empregos na Agência Nacional Para o Emprego da França. A análise é puramente qualitativa, permitindo ver diversos elementos da experiência de desemprego e fatores que a influenciam. Os tipos elaborados independem de sua representação estatística na população global de desempregados.
} 
temporâneas, reconhece-se como legítimo e esperado que o adulto com boa saúde exerça uma atividade profissional. O trabalho propicia segurança material, identidade social e organização do tempo e do espaço cotidiano.

Assim, o estatuto ${ }^{7}$ dos indivíduos é definido em relação ao “"verdadeiro’ emprego”, isto é, o trabalho assalariado estável. Se esse emprego é uma norma social que organiza a vida social (e, consequentemente, a vida de cada indivíduo em particular, orientando seus comportamentos), o afastamento da norma, pela perda do emprego, gera uma perda do estatuto ou, pelo menos, um novo estatuto inferior em relação àquele.

De um modo geral, as mesmas fragilizações psicológicas encontradas entre os trabalhadores desempregados franceses foram constatadas pelos pesquisadores brasileiros Pereira e Brito (1995), que inventariaram as fragilizações psicológicas mais comuns desencadeadas pela perda do emprego: enfraquecimento da autoestima, perturbação da organização temporal, resultando em agressividade e dificuldades nas relações familiares e, por fim, agravamento da depressão em casos de propensão ao problema.

Mas, se o estigma da inutilidade já está geralmente associado ao desemprego, em países em que a regra é "se virar" em "bicos" e outros expedientes irregulares e informais, o autorreconhecimento de um trabalhador, principalmente de classe baixa, como um desempregado pode gerar desqualificações por parte de outros.

Outro depoimento, colhido em pesquisa de campo, demonstra novamente a descrença na boa vontade de quem não encontra emprego:

Eu acho que o emprego está difícil pra quem não procura. Eu não estou procurando agora, que eu estou com criança pequena. Mas está difícil pra quem não procura. Currículos que eu mandei, todo mundo respondeu. Os outros falam assim

Schnapper (1995) entende estatuto "no sentido de um conjunto mais ou menos sistematizado e relativamente fixo de comportamentos complementares que se podem esperar, por um lado, de um indivíduo localizado numa dada situação e, por outro lado, da sociedade em relação a esse indivíduo, e que são reconhecidos como legítimos tanto pelo indivíduo como pela sociedade.” (p.66, trad. livre).

\begin{abstract}
‘ai, eu não consigo achar' mas tem gente que consegue! Está difícil pra quem não procura, que fica em casa e quer arranjar emprego.

(Dona-de-casa, 23 anos, ensino médio completo, sem vinculação com movimentos sociais).
\end{abstract}

Sobre a discriminação que sofre por não encontrar emprego, um trabalhador desempregado comenta:

Aí a gente fica assim vendido, viu? Os vizinhos olham pra gente e falam: "Homão desses, sem trabalho, deve ser vagabundo". E eu procuro, mas não acho, vou fazer o que? Dá vergonha: a mulher sai pra trabalhar de manhã, só volta de noite, e eu em casa, marmanjo velho. Até os meus moleques olham pra mim e eu tenho vergonha de estar em casa.

(Motorista e encarregado de serviços gerais desempregado, 37 anos, segundo grau completo, sem vinculação com movimentos sociais).

Supomos que a vivência do desemprego como inferioridade social, além de constituir uma experiência individual de grande intensidade de sofrimento, também aparece como um fator desfavorável para a mobilização. Como vimos, o sentimento de vergonha atrapalha e impede que se assuma a privação de emprego e se reconheça dentro de uma identidade coletiva de representação política.

De acordo com Demazière (1995b), se o desemprego é uma experiência estigmatizante para a maioria das pessoas, a tendência é que seja negado como fonte de identidade social ou vivido como identidade negativa, que não se deseja afirmar. Seguindo esse raciocínio, entrar numa associação de desempregados significaria aceitar, reconhecerse e ser reconhecido como tal, renunciando a uma identidade de quem busca sair daquela situação.

Demazière (1995a) enfatiza ainda que também as instituições oficiais e privadas voltadas ao tratamento, quantificação e resolução do problema dos desempregados contribuem para seu silenciamento, ao tratar esses trabalhadores como problemas a resolver e ao defini-los por suas carências, faltas e dificuldades, retirando-lhes o va-

${ }^{8}$ Essa moça deu seu depoimento espontaneamente enquanto eu entrevistava a senhora ao seu lado, no CPAT. Com uma filha de colo, deixou de trabalhar fora para cuidar do bebê e estava no local para solicitar bolsa-família. 
lor social. Dessa forma, a maior parte das formas de mobilização em torno do desemprego tende a se constituir em freio à mobilização dos próprios desempregados, por serem fundadas em sua desqualificação social e política.

Essa não é a única dificuldade de construção de uma identidade coletiva a partir do estatuto de desempregado. Segundo Demazière (1995a), a heterogeneidade dos trabalhadores desempregados, no que concerne a suas condições de vida e maneiras de viver o desemprego, consiste num fator desfavorável à sua constituição em atores coletivos.

Estudos sobre desempregados, desenvolvidos em diferentes partes do mundo, mostram a diversidade de posturas, avaliações e estratégias quanto ao desemprego. Schnapper (1994), por exemplo, ao fazer uma enquete com trabalhadores desempregados na França, tipificou três experiências distintas de desemprego. No que ela chamou de experiência do desemprego total, que atinge principalmente pessoas com nível cultural modesto e inserção social frágil, predominam os sentimentos de humilhação, vazio e solidão. Outras pessoas, principalmente mulheres jovens com pouca qualificação profissional, elaboraram a partir do desemprego uma experiência completamente contrária, baseada na valorização do tempo livre para fazer o que realmente se gosta e que não podia ser realizado juntamente com as atividades profissionais até então exercidas; essa vivência foi chamada por Schnapper de desemprego invertido. O último tipo de experiência tipificada foi o desemprego adiado, em que, sobretudo, profissionais mais qualificados investiam tão profundamente na busca de um novo emprego e na qualificação profissional, que tinham a sensação de continuar trabalhando; porém, com o prolongamento do desemprego, tendia a haver, entre eles, o mesmo sentimento de humilhação e culpa vividos pelo primeiro grupo mencionado.

Pesquisando as percepções de trabalhadores desempregados no Brasil, Silva (2009) também confirma que, como já sustentaram Guimarães e Hirata (2004), o desemprego é seletivo, atingindo as pessoas de maneira desigual. Pesam as diferen- ças de idade, a posição na família, o sexo, a qualificação, as possibilidades de uma alternativa de subsistência.

Na pesquisa realizada por Silva (2009), a maior parte dos homens entrevistados declara que o sofrimento em situação de desemprego é maior para quem é chefe de família, seja homem ou mulher, e as mulheres chefes de família dizem que o sofrimento delas é maior. É mais comum que as mulheres se virem em bicos e empregos de estatutos diversos, mas os homens chefes de família também acabam aceitando trabalhos bem precários para sustentar os seus - como confirmam os trabalhos de Jardim (2009) e Segnini (2006).

Também variam as percepções segundo o recorte geracional, segundo Silva (2009). Os mais velhos repetem muito sobre a mudança do mercado de trabalho, que tornou mais difícil, entre o período do seu ingresso e o momento atual, encontrar emprego, especialmente de tipo protegido e estável. Já os mais jovens agem como se sempre tivesse sido assim, pois não conheceram outra situação.

Em geral, entre os jovens, predomina uma crença na qualificação como modo de conseguir um posto de trabalho. A diferença maior entre os jovens está entre morar com os pais ou ser chefe de família. Entre os jovens que moram com os pais, sair de um emprego que não consideram adequado é, às vezes, uma estratégia para tentar um futuro melhor. Para esses jovens que não são provedores, é comum que o desemprego represente principalmente uma privação das possibilidades de consumo, mas não uma ameaça à sobrevivência. Já para os jovens chefes de família, o sustento da família é a primeira coisa a ser ameaçada pelo desemprego e, portanto, a estabilidade é privilegiada em detrimento do progresso na carreira (Silva, 2009).

Outro fator importante para as variações das percepções do desemprego, segundo a pesquisa de Silva (2009), está no recorte da qualificação e escolaridade. Para os mais qualificados, o desemprego é vivido como uma "vergonha", enquanto, entre os menos qualificados, com trajetória de trabalhos precários, o desemprego é só mais um desafio de sobrevivência. Esses últimos, "diante do 
entendimento de que nada poderia melhorar, já que esse é o histórico de suas vidas pessoais e familiares, possuem uma descrença em relação ao trabalho e uma percepção de que a vida de quem é pobre será sempre trabalhar arduamente. Por conseguinte, a experiência do desemprego não é vista como um episódio marcante, mas como um elemento intrínseco da vida dos pobres" (p.191).

Isso não quer dizer que o desemprego não exacerbe, também, para os menos qualificados, o sentimento de desvalorização social e de fracasso social. Mas, por outro lado, eles costumam manifestar orgulho de, mesmo sob condições adversas, terem garantido uma vida digna para si e para seus familiares, com muito esforço. Entre os mais qualificados, há uma identificação positiva do trabalho e uma projeção do futuro a partir da ascensão profissional, o que não ocorre entre os menos qualificados (Silva, 2009).

Dowbor (2004) já afirmava que, para um desempregado voltar o mercado de trabalho, as opções são subjetivamente diferentes, dependendo de onde se venha: para os trabalhadores nãoespecializados, acostumados à insegurança no trabalho, é mais fácil recorrer ao ingresso no mercado informal; já para os especializados, a situação de desemprego prolongado é percebida como mais constrangedora, havendo mais vontade de voltar a uma ocupação de mesmo tipo da anterior e mais resistência a ir para o mercado informal.

Sua forma de buscar emprego, por sinal, dificulta pesquisas empíricas com desempregados de classes mais altas. Uma das raras exceções foi o livro da psicanalista Guilleuse (2009) sobre executivos demitidos em busca de nova colocação. Esse livro mostra o quanto o desemprego é tão mais constrangedor quanto maior é a identificação do sujeito com sua profissão. ${ }^{9}$

${ }^{9}$ Os depoimentos de dois executivos desempregados, João e Fred, mostram sua vergonha em relação ao desemprego: "No começo da semana, fui buscar meu seguro-desemprego, cheguei lá e vi uma fila enorme de desempregados. Tive vontade de sair correndo. [...] Estava morrendo de vergonha e fiquei meio escondido [...]. Lá pelas tantas, depois de uns vinte minutos na fila, eu escuto:

'Oi, doutor João. O senhor por aqui?’. Era o mensageiro que atendia às secretárias da empresa. Eu quase me enfiei dentro do meu jornal” (João). "O pior de tudo é que a gente não desce do salto e não consegue admitir que
Na tese em que analisa os vários recortes geracional, de gênero, de qualificação etc. - sobre as visões formadas pelos trabalhadores sob situação de desemprego, Silva (2009) conclui que "a pesquisa de campo confirmou a dificuldade de apreender homogeneamente o desemprego e revelou um verdadeiro mosaico de significados e vivências que o fenômeno suscita" (p.220). Em suma, o sofrimento subjetivo desencadeado pelo desemprego depende da forma como os indivíduos concebem o trabalho, a trajetória dos pais, os projetos de futuro e os investimentos familiares em seu processo de escolarização ou profissionalização.

A partir daí, pode-se supor que a diversidade nas formas de vivenciar o desemprego dificulta uma luta comum, porque representam modos diferentes de buscar soluções ou de encontrar uma causa comum a situações diferenciadas segundo sexo, idade, trajetória e classe, entre outros fatores.

Aliás, encontrar uma causa clara para o desemprego é um grande desafio para os trabalhadores desempregados, ampliado pela falta de clareza de que o tema se reveste nas sociedades contemporâneas. Se não se conhecem ao certo as causas do desemprego, como lutar contra ele? Quem personifica, para os trabalhadores, os algozes do mal do desemprego?

Em pesquisa de campo com trabalhadores em busca de emprego na cidade de Campinas, as respostas mais comuns sobre as razões para a existência do desemprego no país se referiam à falta de qualificação dos trabalhadores (justificativa bastante repetida pela grande imprensa, em seus discursos sobre a empregabilidade), a falta de vontade do governo de criar empregos e a tecnologia.

É muita tecnologia, né, filha? As máquinas fazem tudo e a gente fica assim sem trabalho.

(Bancária desempregada, 52 anos, ensino médio completo, atualmente fazendo crochê como bico, sem vinculação com movimentos sociais).

somos pessoas como as outras, que temos os mesmos problemas e dificuldades, que não somos mais, e nem sei se um dia fomos, superiores e poderosos. [...] lembrei-me de toda regalia que já tive na empresa. É difíci mesmo abrir mão de tudo. Eu tinha uma casa, um carro, motorista, secretária, office boy, assistência médica para a família toda. Quando fui demitido, tive que sair até da minha própria casa. Foi devastador." (Fred). 
[O desemprego] depende muito dos governantes e da burocracia que eles impõe. Eu, por exemplo, fiz esse curso de porteiro [mostrando o diploma], terminei agora pouco. Talvez eu encontre essa vaga, mas eles provavelmente vão pedir experiência, e nesse serviço, nesse setor, nessa função, eu nunca trabalhei. Talvez eu encontre com facilidade, talvez não.

(Meio-oficial desempregado, 44 anos, ensino fundamental completo, atualmente fazendo bicos como pedreiro, sem vinculação com movimentos sociais).

Sei lá. É muito pouco emprego pra muita gente. E fica mais difícil porque eles pedem segundo grau, curso profissionalizante. Eu estava até falando pra minha colega do lado: agora eu sei o quanto é importante estudar, fazer curso. Pra quem não tem estudo, não fez curso, fica mais difícil. Aí o que vai aparecer é faxina, lavar banheiro. É muito difícil. [...] Isso é assim, não é só coisa do Brasil, isso é coisa do mundo todo, que tá difícil. Você vê gente na fila do emprego. Dizem que antes era mais fácil, mas agora está mais difícil, porque estão exigindo muita coisa. $\mathrm{Na}-$ quele tempo, não exigia tanto.

(Trabalhadora de serviços gerais desempregada, 44 anos, ensino fundamental completo)

Esses depoimentos são representativos, pois confirmam achados de outras pesquisas de campo com trabalhadores desempregados que investigam as razões mais comuns atribuídas ao desemprego: substituição da mão de obra empregada por novos recursos tecnológicos e dificuldade de qualificação dos trabalhadores, além de exigência de juventude ou de experiência, preconceitos contra negros e contra pessoas julgadas pelos selecionadores como de "má aparência” e (ou) que moram em bairros estigmatizados, restrições a mulheres com filhos e políticas públicas e privadas de enxugamento de postos de trabalho (Jardim, 2009; Santos, 2000; Silva, 2009).

Respostas envolvendo questões políticas mais específicas são mais raras, mas existem. Em nossa pesquisa, foram encontradas justamente no discurso de militantes do Movimento dos Trabalhadores Desempregados. Como no trecho abaixo, de uma entrevista com um militante responsável pela organização do movimento em Campinas:

Não precisaria ter desemprego. O padrão tecnológico que a gente tem daria para garantir emprego pra todo mundo. A questão da educa- ção também é limitante. Mas a gente acha principalmente que houve um processo de reestruturação produtiva, de terceira revolução industrial, e essa reestruturação produtiva só serviu pra acumular pro patronato, e não serviu pra poder beneficiar o conjunto da população. Então, o trabalho se reduziu a mão de obra, se mecanizou, informatizou e se deixou amplas parcelas da população à margem de tudo isso. (Militante do MTD-Campinas).

Consideramos que uma visão politizada sobre as origens do desemprego é uma das condições para a construção de uma luta contra o desemprego. Em contrapartida, a impossibilidade de clareza sobre como o desemprego se desenvolve impede pensar que tipo de medidas precisam ser tomadas para combatê-lo. Concordamos com o argumento de Bourneau e Martin (1993) de que a ausência de adversários claramente definidos torna a mobilização mais difícil.

Existem autores que questionam também a possibilidade de construção de um projeto por parte dos trabalhadores desempregados, em grande parte por não terem um lugar na sociedade, reconhecido por outrem ou por eles mesmos.

Esse tema é desenvolvido no livro de Robert Castel, As metamorfoses da questão social (1995). Sua preocupação central é justamente a fragilidade do vínculo social, a incerteza dos estatutos e a ausência de um "lugar social" para uma parte das pessoas, isto é, "a presença, aparentemente cada vez mais insistente, de indivíduos colocados em situação de flutuação na estrutura social e que povoam seus interstícios sem encontrar aí um lugar designado" (1995, p.23).

Castel fala em "zonas" que vão da integração à desfiliação, constituídas de referência a dois eixos: a relação com o mercado de trabalho e com a(s) rede(s) de sociabilidade primária. A primeira zona é caracterizada pelo trabalho estável e pela inserção relacional sólida. No meio, encontra-se uma zona intermediária de vulnerabilidade social, que combina precariedade do trabalho e fragilidade dos suportes de proximidade. Como zona extrema, no lado negativo do processo, está a desfiliação, caracterizada pela ausência de participação em qualquer atividade produtiva e pela fra- 
gilidade dos suportes de proximidade

Nessa ultima situação, as pessoas são consideradas, numa sociedade marcada pelos valores utilitaristas do mundo industrial, como "inúteis para o mundo". Desqualificando-as também no mundo cívico e político, essa "inutilidade" as torna "não-forças sociais", no sentido de que elas não têm poder de influência sobre os rumos da sociedade. Enfim, elas não têm existência social, ou seja, não encontram um lugar reconhecido na sociedade. Pela sua ausência de lugar reconhecido, Castel (1998) as chama de supranumerários, não-integrados nem integráveis na sociedade no sentido da solidariedade orgânica durkheimiana, ou seja, não pertencentes como elementos interdependentes no conjunto da sociedade. Essa inutilidade as desqualificaria no plano cívico e político, tirandolhes influência no rumo dos acontecimentos sociais. Por isso, Castel diz que são "não-forças sociais". Suas manifestações se restringiriam à violência esporádica e sem orientação precisa. Para que houvesse realmente luta social, seria necessário que houvesse um coletivo e um projeto de futuro.

Trata-se da mesma ideia de Soulet (1994), de que indivíduos em situação de exclusão do mercado de trabalho encontram-se atomizados, não formam um grupo organizado, nem são portadores de um projeto social para assegurar o controle social das orientações normativas e culturais da sociedade (1994).

Martins (2002), igualmente, considera que os trabalhadores excluídos do mercado de trabalho não têm potencial para se constituírem em sujeitos sociais transformadores. Privados da participação direta no processo produtivo, eles estariam privados também de formas eficientes de luta (tais como as greves) que interferissem nesse processo:

Eles não protagonizam nem realizam uma contradição no interior do processo produtivo, que ao mesmo tempo produz coisas e produz, ou reproduz, relações sociais, as relações fundamentais à produção e realização da mais-valia e, sobretudo, fundamentais às novas formas, especulativas e rentistas, de acumulação de capital. Eles são apenas o trabalhador potencial, o resíduo crescente do desenvolvimento econômi- co anômalo. Quando muito, são trabalhadores dos setores secundários e irrelevantes da produção. Por isso são excluídos. Não só, nem principalmente, excluídos das oportunidades de participação social. Mas, excluídos das possibilidades ativas do fazer História. [...] Não podem impregnar por dentro o processo de reprodução ampliada do capital. A produção de novas situações e de novas relações sociais se dá sem eles. E a reprodução se dá sem sua participação direta. Diferente de quem efetivamente trabalha e é vital para o processo de acumulação ampliada do capital. São descartáveis. Esse é o extremo histórico da coisificação da pessoa e de sua alienação. (Martins, 2002, p.35)

Segundo Martins (2002), as formas de protesto que têm ocorrido no país nos últimos anos invasões, passeatas, linchamentos, quebra-quebras etc. - são também conservadoras, pois não contêm um conteúdo político nem comprometem "a reprodução do ‘sistema”'. Pelo contrário, seu foco é a integração no existente, pela via do consumo.

Se isso é verdade, as formas de luta que se verificam se dão entre os que se encontram nas mesmas condições precárias, em disputas individualistas por oportunidades melhores.

Nessa linha de Martins (2002), de que os excluídos querem entrar no mundo do consumo, Soulet (1994) e Karz (2000) afirmam que tudo que os out querem é ser in. Se tomarmos essa afirmação como válida, fica difícil pensar a possibilidade de formação de um projeto coletivo, no lugar do qual haveria apenas uma luta por determinadas posições na estrutura social tal como ela se encontra, e que tende a ser uma luta individualizada e interna ao próprio conjunto de "excluídos". Afinal, quando os out querem ser in, há pouca evidência de contradição e de enfrentamento de interesses opostos. Sob tal perspectiva, o sentimento de insegurança frente à precarização e às incertezas sobre a sobrevivência substituiria a consciência de classe.

A própria possibilidade de construção de uma consciência de interesses comuns pode ficar prejudicada pelo isolamento causado pelo desemprego. A vergonha pelo desemprego, mencionada por vários pesquisadores empíricos da situação dos desempregados (Santos, 2000; Silva, 2009; 
Schnapper, 1994) e discutida algumas páginas atrás, é um fator relevante para o isolamento. A depressão causada pela situação difícil (Santos, 2000; Silva, 2009; Schnapper, 1994) também pode ser apontada como tendo a mesma consequência. Além disso, para muitos, a sociabilidade com os colegas de trabalho é a mais forte, além da família, e também ela fica desfeita quando se é mandando embora de um trabalho.

Além de todos os obstáculos assinalados pelas pesquisas já existentes sobre o tema do desemprego, alguns outros fatores específicos de dificuldade para a organização coletiva contra o desemprego são sugeridos por nossa pesquisa de campo, em andamento.

Militantes do Movimento dos Trabalhadores Desempregados, em Campinas e o Rio de Janeiro, relataram conflitos com o crime organizado, quando um dos núcleos do movimento se instalava em uma favela do Rio de Janeiro. Alguns anos atrás, os militantes chegaram a ser expulsos por não permitirem instalar uma boca de fumo dentro da ocupação, e lideranças foram ameaçadas de morte por traficantes locais. Também na cidade de Sumaré (SP) foi relatada a expulsão dos militantes de um bairro da periferia por traficantes.

Como o MTD conecta a luta por trabalho com a luta por moradia, adotando como um dos seus meios de ação as ocupações de terrenos urbanos, isso também tem o potencial de gerar tensões com a polícia, como já ocorreu em desocupações nos municípios de Campinas (SP) e do Rio de Janeiro. O que não é de se espantar numa sociedade com tradição de confundir questões sociais com casos de polícia.

Não é incomum que a menção a um movimento de trabalhadores desempregados suscite certa desconfiança em pessoas que o desconhecem. Nesse sentido, é comum para um pesquisador dos movimentos dos desempregados ouvir (como aconteceu a respeito da presente pesquisa) frases como: "Não seria melhor se eles [os trabalhadores desempregados] fossem procurar emprego, em vez de ficar gastando tempo fazendo movimento?" (de uma jornalista de 40 anos). Ou: "Sei não, não me espanta se esses líderes desse movimento estiverem usando isso como escada para serem um dia deputados ou coisa do tipo." (de um professor universitário de 37 anos).

Nessas afirmações, está implicada a ideia de que uma luta contra o desemprego não deve ser politizada, e quem a politiza está com más intenções. Se não deve ser politizada, é porque é uma questão individual, e não um problema criado socialmente e, por isso, deve ser solucionado coletivamente.

Não apenas na classe média se percebe essa individualização. Também na maior parte das entrevistas com trabalhadores desempregados com baixa qualificação e baixa renda (19 num total de 32 entrevistas), apareceram afirmações de que a solução para o desemprego é exclusivamente estudar, se qualificar mais, buscar uma profissão que esteja em alta no mercado, estar disponível "para qualquer trabalho" - todas elas, soluções individualizadas.

A pesquisa de Nancy Pereira (2007) com grupos do MTD confirmou essa visão de mundo. Os grupos participantes da pesquisa-ação perceberam que o que se vê na imprensa e nas propagandas é a ideia de que o emprego existe e a culpa pelo desemprego é dos indivíduos que não conseguem chegar a ele (porque não estão qualificados ou não têm experiência ou não sabem se comportar numa entrevista etc.). Todas as informações divulgadas se voltam para a explicação de como fazer currículo, como se comportar numa entrevista, como se preparar para concursos etc. Segundo os mesmos grupos, formas semelhantes de tratar o problema são apresentadas por igrejas das mais variadas religiões, que oferecem meios místicos para que cada pessoa procure uma saída particular para o desemprego em sua família: no mercado da fé, o emprego torna-se mercadoria que o fiel vai trocar com Deus. Em ambos os casos, vemos a manutenção de uma atitude individual em relação às alternativas ao desemprego, como reflexo de uma atribuição da culpa do desemprego ao desempregado, e não a uma estrutura e conjuntura político-econômica. Na pesquisa de campo que temos feito, também há casos (10 entrevistados, num grupo de 32), em que aparece um embrião de politização da ques- 
tão do desemprego, quando os trabalhadores são perguntados sobre como resolver o desemprego. Mas as respostas se concentram na ideia de que "o governo tem que resolver". Sobre como fazer isso, obtivemos as seguintes respostas: "criar empregos”, "fazer as firmas terem mais empregos", "dar os cursos certos pra gente poder ter o que os patrões exigem da gente".

A resposta à pergunta sobre o conhecimento fr movimentos de desempregados foi unânime entre os 32 trabalhadores desempregados entrevistados na cidade de Campinas: ninguém tinha ouvido falar sobre isso, nem nessa cidade nem em outra. Mas, sobretudo, a maioria dos trabalhadores que participou da entrevista não tinha uma ideia clara do que significava um movimento social. Apenas dois associaram o termo a "protestos por melhorias na vida dos trabalhadores" e a "procurar direitos" (respectivamente, um motorista desempregado de 27 anos com ensino médio completo e um homem de 44 anos, que estudou até a oitava série e faz "bicos" de pedreiro, estando sem registro em carteira há mais de dois anos). Os demais trabalhadores disseram não saber o que poderia fazer um movimento de trabalhadores desempregados ou o associaram a uma agência de procura de emprego, a uma instituição de assistência social ou a uma instituição governamental de mediação entre empresas e trabalhadores. Parece haver, enfim, um desconhecimento generalizado sobre a possibilidade de uma luta coletiva e politizada.

\section{POSSIBILIDADES DALUTA COLETIVA}

Ainda que seja difícil a construção de um projeto comum a partir da situação atomizada dos trabalhadores desempregados, se há muitos movimentos que se formam a partir da identidade de "sem" (sem-terra, sem-teto, sem-trabalho...), algo deve explicar sua existência.

Uma explicação pode ser buscada em E.P. Thompson (1984), em seu estudo sobre a formação da classe operária inglesa: o pertencimento a uma classe (ou a uma categoria), sua identidade e seu projeto se constroem na mesma medida em que se processa sua organização e sua luta coletiva. Assim, talvez, o pertencimento a um grupo em luta por outras questões que não o trabalho (movimentos de bairro, movimentos por carências específicas, sindicatos quando empregados etc.) facilita a evolução para a identidade de sem-trabalho e a luta em torno dela. Em outras palavras, se os passos de certa luta forem pensados apenas sob uma determinada ordenação temporal necessária - primeiro, é preciso ter força política e um projeto bem definido; depois, organizar-se para promovê-lo-, realmente parece que o desenvolvimento do processo é impossível; contudo, a luta, a formulação de um projeto e o fortalecimento como grupo com objetivo comum não constituem necessariamente fases rigidamente separadas.

A luta de um grupo com identidade negativa é também a luta pela ressignificação dessa identidade. É o que percebem pesquisadores em movimentos sociais específicos. Del Prette (1990) pesquisou um movimento de trabalhadores desempregados formado e dissolvido na cidade de São Paulo em meados da década de 1980 e explica assim sua existência:

Se, de um lado, a categoria desempregado não
provia ao trabalhador nenhuma identidade soci-
al positiva e, mesmo, podia afetar-lhe a identida-
de pessoal, de outro lado, a sua filiação a um
movimento reivindicativo de direito ao trabalho,
ainda que expondo socialmente a sua situação,
representava a possibilidade de superação de
sentimentos negativos e de construção de uma
nova identidade social ligada ao exercício da ci-
dadania (Del Prette, 1990, p.245).

Não é por acaso que o Movimento dos Trabalhadores Desempregados, na década de 2000, faz questão de ressaltar sua identidade não só de desempregados, mas de trabalhadores desempregados - como uma liderança do MTD em Campi- 
nas fez questão de ressaltar durante a entrevista:

Você não pense que o trabalhador desempregado não trabalha. Nós somos o movimento dos trabalhadores desempregados, e não dos desempregados. Se você for avaliar, o trabalhador desempregado, ele trabalha muito pra sobreviver, ele é o precarizado. (Militante do MTD-Campinas).

$\mathrm{O}$ ato de assinalar que os desempregados são trabalhadores, e que trabalham muito, faz lembrar que o movimento tem a capacidade - e talvez o papel - de reafirmar, com a categoria "trabalhador", uma identidade positiva que se soma à categoria desqualificada de desempregado. Por um lado, é uma defesa contra aqueles que julgam os desempregados como "vagabundos", ou o movimento social como criminoso ou arruaceiro. Por outro, é uma maneira de os próprios integrantes do movimento afirmarem para si mesmos uma identidade positiva.

Também Demazière (1995a) constatou, no mesmo sentido, que

Quaisquer que sejam as tentativas de mobilização coletiva e de expressão pública, elas testemunham transformações do estatuto do desempregado: se ele permanece uma condição social desvalorizada, ele, contudo não é mais sistematicamente vivido e percebido como vergonhoso e pode, em certos casos, constituir a base de uma identidade coletiva. Nesse sentido, a observação mais microssociológica da vivência do desemprego interpela a dinâmica de construção identitária dos sem-trabalho, interroga as mutações do lugar do desemprego nas representações sociais, questiona as evoluções da posição do desempregado na organização da sociedade (1995a, p.113, trad. livre).

As indicações oriundas do cotidiano dos movimentos sociais parecem confirmar o que Honneth (2003) percebe ao formular a teoria do reconhecimento como base para lutas coletivas: a participação num movimento social pode ser um modo de encontrar solidariedade e reconhecimento que não são vivenciados fora dali.

Quanto à questão da vergonha do desemprego como um fator paralisante, encontramos também um argumento contrário em Honneth (2003). Ele mostra que a vergonha também pode ser um impulso para a luta. Se as pessoas experimentam uma quebra de expectativa em relação ao que esperam como resposta para suas ações, suas reações variam segundo o sujeito a quem atribuam a causa dessa quebra: se são elas mesmas, o sentimento tende a ser de culpa; se os culpados são outros, o sentimento deverá ser de indignação moral. Nesse caso, experimenta-se o sentimento de ser desrespeitado, o que pode ser base para a construção de uma luta coletiva.

Pensando nesses termos a possibilidade de construção de uma luta coletiva por trabalhadores desempregados, pode-se dizer que seu potencial existe quando aqueles sujeitos percebem que sua situação foi gerada por decisões de outros agentes (não necessariamente de modo deliberado para lhes causar essa situação, mas para perseguir objetivos próprios em ações que, inter-conectadas, levam à diminuição dos postos de trabalho), que suas ações individuais, para estarem aptos ao mercado de trabalho, não geram a resposta esperada, não por sua culpa, mas por circunstâncias determinadas socialmente e que essas circunstâncias os humilham e descumprem aquilo que se espera de um contrato social legítimo nas sociedades de trabalho assalariado sob cujos princípios esses sujeitos foram socializados (no caso, a garantia de que todos possam ter acesso à satisfação de suas necessidades materiais se estiverem dispostos a trabalhar, a promessa de que todos os cidadãos tenham direito ao trabalho).

\section{CONSIDERAÇÕES FINAIS}

Várias dificuldades pesam contra a organização coletiva de trabalhadores desempregados. Entre elas, é central a vivência do desemprego como experiência de inferioridade social. Esse modo de os trabalhadores desempregados se verem e serem vistos é condicionado pela visão de mundo dominante do trabalho assalariado como norma social, mesmo quando os postos de trabalho existentes não correspondem ao número de pessoas que querem ocupá-los. No caso do Brasil, entre outros países, o estigma de "vagabundo" atribuído a quem 
está desempregado é acentuado pela informalidade presente em toda a história do país, na medida em que se cria o padrão de os trabalhadores aceitarem "se virar" em expedientes precários para assegurar a sobrevivência, e o desemprego oculto por trabalho precário tem recorrentemente sido mascarado. Além disso, o isolamento proporcionado pelo corte dos vínculos de trabalho também dificulta a criação de laços associativos.

A ausência de clareza sobre os fatores que levam ao desemprego e as formas de resolver o problema, junto com a despolitização do tema, também dificultam pensá-lo coletivamente. Enquanto se buscam soluções individuais, a competição entre os trabalhadores nas mesmas condições de desemprego substitui a busca de um projeto comum. A possibilidade de organização coletiva também se ressente da falta de um adversário claramente definido.

Quando, apesar desses obstáculos, consegue-se começar uma organização, com métodos como a ocupação de terrenos para moradia e trabalho, esse fato vem acompanhado de novos obstáculos, na forma de conflitos com outros agentes sociais, como grupos criminosos, grupos econômicos capitalistas e polícia.

Em que pesem todas as barreiras à organização coletiva e politizada de trabalhadores desempregados, existem também as possibilidades para que esse caminho de concretize. A vergonha de certa condição (por exemplo, de desempregado), apesar de poder ser paralisante, também pode ser um impulso para a luta, quando o sujeito percebe que sua situação é causada por um fator externo, de responsabilidade de outros agentes sociais caso em que o sentimento de ser desrespeitado pode levar à indignação moral e constituir-se em base para a construção de uma luta coletiva. Por fim, a participação em um movimento social desse tipo pode ser motivada pela possibilidade de o sujeito encontrar ali uma solidariedade e um reconhecimento que não consegue experimentar em outra parte.

Enfim, o sentimento de pertencimento a uma categoria, uma identidade coletiva e um projeto de futuro constroem-se ao longo do processo de organização e de luta de um grupo. É, portanto, provável que o pertencimento a um grupo em luta por outros direitos seja um facilitador para a construção de um movimento de trabalhadores desempregados.

(Recebido para publicação em 10 de agosto de 2010) (Aceito em 18 de março de 2011)

\section{REFERÊNCIAS}

BOURNEAU, Martin. Organizer les sans-emploi L'experience de l'APEIS dans le Val-de-Marne. In FILLEULE, O. (Dir.) Sociologie de la protestation. Les formes de l'action collective dans la France contemporaine. Paris: L'Harmattan, 1993.

CASTEL, Robert. Les metamorphoses de la question sociale: une chronique du salariat. Paris: Fayard, 1995.

Centralité du travail et cohésion sociale. In: KERGOAT, Jacques et al. (Dir.). Le monde du travail. Paris : La Découverte, 1998. p.50-60.

DEL PRETTE, Almir. Movimentos sociais em uma perspectiva psicológico-social: o movimento de luta contra o desemprego. 1990. Tese (Doutorado em Psicologia) Universidade de São Paulo. São Paulo: 1990.

DEMAZIÈRE, Didier. Sociologie du chômage. Paris: La Découverte, 1995a.

Le chômage de longue durée. Paris: Presses Universitaires de France, 1995b.

Dowbor, Ladislau. Desafios do trabalho. Petrópolis: Vozes, 2004.

GUILLEUESE, Mariá. O mal estar-no mundo corporativo. 2.ed. São Paulo: Editora Gente, 2009

GUIMARÃES, Nadya Araújo. Por uma sociologia do desemprego. Revista Brasileira de Ciências Sociais, São Paulo, v.17, n.50, out., 2002.

- HIRATA, Helena. Caminhos cruzados: estratégias de empresas e trajetórias de trabalhadores. São Paulo: Ed.34, 2004.

Transições ocupacionais e representações sobre a procura de trabalho: comparando mercados de trabalho sob distintos regimes de welfare (São Paulo, Paris e Tóquio). Disponível em: http://www.fflch.usp.br|sociologia nadya.transicoes.pdf. Acesso em: 20 fev. 2009.

GOULART, Patrícia Martins. Sem medo do desemprego: o caso do movimento dos trabalhadores desempregados. Psicologia e Sociedade, São Paulo, v.1, n.1, p.137-160, jan./jul., 2003.

HONNETH, Axel. Luta por reconhecimento: a gramática atual dos conflitos sociais. São Paulo: Editora 34, 2003.

HIRATA, Helena; Humphrey, John. Trabalhadores desempregados: trajetórias de operários e operárias industriais no Brasil. Revista Brasileira de Ciências Sociais, São Paulo, n.11, v.4, out., 1989.

JARDIM, Fabiana. Entre desalento e invenção: experiências de desemprego e desenraizamento em São Paulo. São Paulo: Annablume; Fapesp, 2009. 
KARZ, Saul. L'exclusion: faux concept, vrai problème. In: (Dir.) L'exclusion, finir pour en finir. 2.ed. Pa-

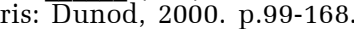

LEITE, Marcia de Paula. O trabalho no Brasil dos anos 2000: duas faces de um mesmo processo. In: ENCONTRO DA ABET, dez. 2009. (mimeo.)

MARTINS, José de Souza. A sociedade vista do abismo: novos estudos sobre exclusão, pobreza e classes sociais. Petrópolis: Vozes, 2002.

PAUGAM, Serge. La disqualification sociale: essai sur la nouvelle pauvreté. Paris: Presses Universitaires de France, 1994

PEREIRA, Nancy Cardoso. O que transforma o mundo é a necessidade: educação e trabalho no MTD. Porto Alegre, 2007. (mimeo.)

PIGNONI, Maria-Teresa. Desemprego e mobilizacão de desempregados a França e na Itália. In: GUIMARÃES Nadya Araujo; HIRATA, Helena (Org.). Desemprego: trajetórias, identidades, mobilizações. São Paulo: Editora Senac, 2006. p.271-303.
SANTOS, João Bosco Feitosa dos. $O$ avesso da maldição do gênesis: a saga de quem não tem trabalho. São Paulo: Annablume; Fortaleza: Secretaria da Cultura e Desporto do Governo do Estado do Ceará, 2000.

SCHNAPPER, Dominique. L'épreuve du chômage. 5.ed. Paris: Gallimard, 1994.

SEGNINI, Liliana R.P. Vivências de mulheres em situação de desemprego. São Paulo em Perspectiva, São Paulo, v.20, n.4, p.58-72, out./dez., 2006.

SILVA, Marineide Maria. O mosaico do desemprego. 2009 Tese (Doutorado em Ciências Sociais) - UNICAMP. Campinas: 2009 .

SOULET, Marc-Henry. Penser l'exclusion aujourd'hui: non-intégration ou desintégration? In: (Dir.) De la-non-intégration: essais de définition théorique d'un problème social contemporain. Fribourg (Suisse): Éditions Universitaires Fribourg Suisse, 1994. p.1-9.

THOMPSON, Edward P. Tradición, revuelta y consciencia de clase: estudios sobre la crisis de la sociedad preindustrial. Barcelona: Editorial Crítica, 1984. 


\section{UNEMPLOYED WORKERS AND COLLECTIVE STRUGGLE: difficulties and possibilities}

\author{
Giuliana Franco Leal
}

This article proposes a discussion about the possibilities of collective reaction, towards unemployment by the unemployed workers. It performs a literature review and a field research of qualitative nature, based on semi-stuctured interviews with worker who are not involved in social movements regarding the unemployment question, in Campinas (São Paulo) and activists of the movement of unemployed workers, in the cities of Campinas and Rio de Janeiro. Developing hypothesis about what are the obstacles and impulses for unemployed workers organize themselves into associations aiming to defend their interests.

KEY WorDS: unemployment, unemployed worker, social movement, social class, social struggle.

\section{CHÔMEURS ET LUTTE COLLECTIVE: difficultés et possibilités}

\author{
Giuliana Franco Leal
}

Cet article propose une discussion concernant les possibilités de réaction collective des chômeurs face au chômage. On y présente une recherche bibliographique et une recherche qualitative effectuée sur le terrain avec des interviews semi-structurées faites auprès de travailleurs de la municipalité de Campinas (État de São Paulo) qui ne font pas partie des mouvements sociaux concernés par le chômage. Des militants appartenant à un groupement de chômeurs dans les villes de de Campinas et de Rio de Janeiro ont aussi été interviewés. Des hypothèses ont été avancées à propos des obstacles et des motivations capables de mobiliser les chômeurs pour qu'ils s'organisent en association pour défendre leurs intérêts.

MOTS-CLÉs: chômage, chômeurs, mouvements sociaux, classes sociales, lutte sociale.

Giuliana Franco Leal - Doutora em Sociologia pela Universidade Estadual de Campinas. Professora do Campus de Macaé da Universidade Federal do Rio de Janeiro. Desenvolve pesquisas na área de trabalho e desigualdades sociais. Sua mais recente publicação é o livro Exclusão social e ruptura dos laços sociais: análise crítica do debate contemporâneo, publicado pela Editora da Universidade Federal de Santa Catarina em 2011. 